\title{
Ethiek van de macht
}

\section{Over de moed van de held}

Erik Pool*

De thematiek van macht en tegenmacht wordt doorgaans opgevat als een kwestie die speelt tussen organisaties en instituten. De Binnenhof-discussies concentreren zich op de verhoudingen tussen staatsmachten, waaronder de onafhankelijkheid en toegankelijkheid van de rechtspraak en de macht van het parlement ten opzichte van de regering (Tjeenk Willink, 2021). Het geheel is uit balans. In dit discours over de formele verhoudingen, verantwoordelijkheden en geformaliseerde rechten en plichten speelt kritiek op cultuur en omgangsvormen een belangrijke rol. De vertaling daarvan naar het persoonlijk of individueel handelen van de mensen die in de instituten werken, krijgt relatief weinig aandacht. Toch zit daarin waarschijnlijk een sleutel voor de noodzakelijke cultuurverandering. De problemen met de rechtsstaat zijn niet alleen van formele aard, maar evenzeer informeel van karakter. Dat informele gebied behoort tot het domein van de ethiek. De crisis in de rechtsstaat is daarom te begrijpen als een morele crisis (Brenninkmeijer, 2019). Om werkelijk een verandering te bewerkstelligen die doorwerkt in het hele overheidssysteem behoeven naast de meer bestuurlijk-juridische vragen vooral de ethische, morele kwesties aandacht, op individueel én collectief niveau. Dat is overigens geen eenvoudige opgave, omdat in moderne samenlevingen dit morele discours op de achtergrond is geraakt (Dohmen, 2007; Verbrugge, 2004; Taylor, 1989).

De noodzaak om moreel, ambtelijk leiderschap te ontwikkelen is het uitgangspunt van mijn derde publicatie over ambtelijke tegenspraak: Macht en moed. Ambtelijk vakmanschap en de kunst van het tegenspreken (Pool, 2021). In dit pleidooi voor tegenspraak en herwaardering van ambtelijk vakmanschap spelen de ontwikkeling en doorwerking van een gezonde moraal een kardinale rol. Het is ook een antwoord op de rechtsstatelijke crisis die zich aandiende in de kinderopvangtoeslagaffaire (Parlementaire Ondervragingscommissie Kinderopvangtoeslag, 2020). Ik denk dat het publieke en professionele debat over het functioneren van de overheid of de rechtsstaat gediend is met een uitwisseling tussen filosofie, moraal en politiek (Roovers, 2016). Filosofie helpt om goed na te denken en de zaken anders, fundamenteler te bekijken. Moraal is een onmisbare schakel voor het goede leven, waar zowel de gezamenlijke als de individuele inspanning van mensen binnen een democratie op is gericht. Politiek is het domein van de collectieve verantwoordelijkheid met spelregels en tradities die onderhoud behoeven, elke dag opnieuw in de taaie praktijk van ambtelijk werk, bestuur en democratische legitimatie (Koole, 2021).

* $\quad$ Erik Pool, BA is programmadirecteur Dialoog en Ethiek bij het ministerie van Binnenlandse Zaken en Koninkrijksrelaties. 


\section{Tegenspraak}

Die mix van invalshoeken uit filosofie, moraal en politiek is ook zichtbaar in mijn eerdere essays over tegenspraak. Weerwoord en waarheid (Pool, 2017) problematiseert de tegenspraakthematiek en onderzoekt wat 'speaking truth to power' zo moeilijk maakt. Daarin behandel ik een tolerante organisatiecultuur en de wens tot leren en vertrouwen stellen in de wetenschap. Liefde en leiderschap (Pool, 2018) verkent waarom leiders de omgang met tegenspraak zelf zo moeilijk vinden en waarom het zo belangrijk is voor een gezonde werkgemeenschap dat zij ontvankelijk zijn voor kritische, afwijkende stemmen. Stijl van leiden, mensen serieus nemen en het goede gesprek leren voeren, zijn in Liefde en leiderschap dragende thema's.

In Macht en moed (Pool, 2021) ga ik verder in op nut en noodzaak van een op dialoog gebaseerde cultuur in overheidsorganisaties. Het vermoeden is dat ambtenaren door middel van frequente dialoogsessies over professionele en ethische vraagstukken na verloop van tijd nieuwe routines zullen opbouwen die bevorderlijk zijn voor het vrijuit bespreken van de zaken die hen bezighouden of dwarszitten. In vrije gesprekken zijn de omstandigheden optimaal om in gesprek met anderen verwaarloosde gewetensvragen te doordenken, vertrouwd te raken met ethisch jargon en en passant de eigen morele autonomie te versterken. De deelnemers putten uit hun eigen levenservaringen, geholpen door een hierbij passende gespreksopbouw en ondervragingsmethodiek die is gegrondvest in de dialogen van Socrates die Plato te boek stelde (Kessels, 2012; Sluiter, 2014).

Door geregeld aan vrije gesprekken deel te nemen worden ambtenaren zich gaandeweg meer bewust van de eigen positie en verantwoordelijkheden, waarna zij dat bewustzijn kunnen inzetten in de uitoefening van de opgedragen taken. Zo kan de vrije ruimte ervoor zorgen dat ambtenaren wat meer afstand gaan ervaren tot de politieke dynamiek die hun dagelijkse werk nu tekent. Met anderen (Frequin, 2021; Bekker, 2020) constateer ik dat het ambtelijke werk te zeer wordt beheerst door de invloed van actuele politieke (coalitie) issues en de mediagevoelige, incidentgedreven kortetermijnvragen die het debat tussen de bewoners van het Binnenhof lijken te beheersen. Ambtenaren zijn in deze dynamiek van 'politiek met een kleine p' ('t Hart, 2014) te veel meegegaan, waardoor ze steeds minder toekomen aan een meer neutrale, onafhankelijke advisering, het inbrengen van hun deskundigheid en kennis, het grondig verkennen van voors en tegens van plannen, en het ontwikkelen van alternatieve scenario's om te kunnen beoordelen welke optie maatschappelijk goed uitpakt, haalbaar en uitvoerbaar is.

\section{Andere kennis}

Om de betekenis en meerwaarde van mijn voorstellen in Macht en moed goed te begrijpen is het van belang onderscheid te maken in soorten kennis. Jos Kessels is in het Nederlandse taalgebied op dit terrein een van de meest gezaghebbende stemmen. In Socrates op de markt werkt hij het onderscheid uit tussen kennis die 
wel en kennis die niet doorwerkt in het handelen. Kennis die geen doorwerking krijgt in het gedrag van de persoon die deze kennis heeft, is geen ware kennis (Kessels, 1997). Hij verklaart het al dan niet doorwerken van kennis uit het ontstaan ervan. De ideeën en inzichten die we via externe bronnen of van anderen krijgen aangereikt, beklijven niet indien deze niet kunnen meedoen in hoe we zelf leven, werken, spreken, denken, voelen. Kessels:

'Dit probleem hangt nauw samen met het (...) verschijnsel dat wij kennis vaak beschouwen als iets externs, een geheel van vrijblijvende ideeën of in boeken opgeslagen wetenswaardigheden, in plaats van als een conceptuele structuur die nauw verweven is met ons eigen handelen, onze houding, onze hele persoonlijkheid. Wij zijn gewend geraakt wat iemand weet te beschouwen als losstaand van wie of wat hij is. Daarom is het geen wonder dat veel van onze kennis onwerkzaam is. Zij zit immers alleen in ons hoofd, zij is niet geïntegreerd in ons handelen. Pas door dit schijnleren te ontmaskeren en te scheiden van wat wij werkelijk weten, ontstaat de mogelijkheid dat onze kennis werkelijk effectief wordt. Maar dat is iets wat een ander niet voor ons kan doen, het kan alleen door onszelf gedaan worden. Daarvoor moeten we zelf nadenken, zelf argumenten afwegen, zelf onze eigen kennis onderzoeken, ook als groep. Ook hiervoor is dialectiek onontbeerlijk.'

Daarom is het voeren van socratische gesprekken waarin de dialectiek volop beproefd en benut kan worden, een relevante reactie op de problemen die we bij de overheid signaleren. Als het waar is dat onze manieren van denken en doen, dat onze gewoontes en onze werk- en leercultuur toe zijn aan een grondige herijking, dan is het van groot belang dit type didactische inzichten te benutten voor het ontwerpen van een adequate aanpak. Het starten en doorontwikkelen van een omvangrijke socratische dialoogcultuur is daarom een aan te bevelen aanpak.

In de bedoelde dialogen zijn de morele of ethische vragen die werkers bij zich dragen leidend. Dat kunnen bijna praktische vragen zijn, bijvoorbeeld als het gaat om het prioriteren van activiteiten. Dat kunnen ook meer principiële kwesties zijn, bijvoorbeeld de keus tussen de opdracht uitvoeren zoals die is opgedragen of teruggaan naar de opdrachtgever omdat er twijfels zijn over de juistheid, haalbaarheid of rechtvaardigheid van de klus.

Voor al dergelijke vragen bestaan geen goede of juiste antwoorden. Het is geen wetenschap, het is ethiek. Het is leren van elkaars antwoorden en perspectieven. En van zelfinzicht. Het is wat Aristoteles niet-noodzakelijke kennis noemde, waarmee hij niet bedoelde dat het kennis betreft die onnodig zou zijn. Het betreft hier kennis die niet wordt veroorzaakt door een natuurwet die wetenschappelijk vast te stellen valt. De geest is aan het werk, zeggen we Hannah Arendt na (Arendt, 2020). Het is ethiek. Dan gebeurt er van alles, tussen mensen onderling, maar wat precies?

Voor de ethiek is ons wetenschappelijk vermogen, de kennis die epistème werd genoemd, niet genoeg. Na de objectieve feiten is het aan ons ethos, onze moreel ge- 
vormde grondhouding van waaruit we op een natuurlijke manier hebben leren handelen. Hier komt het aan op de praktische kunde en levenswijsheid. Het is deze phronêsis die verraadt of we in praktische zin tot wijze besluiten en goede projecten kunnen komen. (Aristoteles)

Er is wel een bepaalde grondthematiek die in elk gesprek meedoet. Het draait in zekere zin telkens om de vraag wie we zijn en hoe we met anderen samen willen of moeten leven en werken. Het goede leven is hierin het klassieke streven. De vragen begrijpen we als uitingen van de zoektocht naar de zin van moderne mensen die hun levens zinvol willen vormgeven (Dohmen, 2007; Pool, 2014, 2020). Deze thematiek van de zogeheten levenskunst is evenwel te algemeen om als concreet gespreksonderwerp te dienen. Daarom zoekt een groep naar een relevante toespitsing en formuleert een prangende, gewetensvolle vraag of kwestie. Mogelijke thema's zijn: de mens- en maatschappijopvatting die in het beleidswerk zit versleuteld, de verhouding van ambtenaren ten opzichte van politiek bestuurders, de moeizame uitvoerings- en handhavingspraktijken, individuele ethiek versus teammentaliteit, opdrachtnemers en hun autonome verantwoordelijkheid, de (in)consistentie van beleidsinhoud en organisatiecultuur. De lijst is niet limitatief, dat is immers de essentie van vrije gesprekken: die gaan over alles wat de deelnemers aan het hart gaat.

\section{Gespreksvormen}

We kunnen grofweg drie grondvormen van vrije, filosofische gesprekken onderscheiden die collectief leren ondersteunen.

In socratische dialogen zoeken we antwoorden bij een gewichtige vraag aan de hand van concrete, persoonlijke ervaringen. We zoeken in de ervaring naar verborgen inzichten en morele principes die blijkbaar aan het werk zijn. We brengen een karakteristieke ervaring minutieus in beeld en verplaatsen ons in de betreffende situatie. We vertellen elkaar hoe verschillend we in die omstandigheid wellicht zelf zouden denken, voelen en handelen. We leren onszelf kennen op een bijzondere manier. (Kessels, 1997)

In morele beraden of ethische dilemmagesprekken verkennen we de aard van de spanning die in een bepaalde situatie of bij een bepaald voorval onoplosbaar blijkt te zijn. We zoeken naar een passende, ethische verantwoording van genomen of te nemen beslissingen. Het beraad is erop gericht de morele kwesties en vragen onder ogen te zien, openhartig te bespreken en dialogisch te onderzoeken. Het kan bedoeld zijn om de kwaliteit van beslissingen te beoordelen, maar kan ook gericht zijn op het verhelderen, begrijpen en onderzoeken van elkaars posities en standpunten (www.isvw.nl).

In filosofische onderzoeken verkennen we welke aspecten een rol spelen bij een vraagstuk of kwestie en zoeken we naar een richtinggevende visie die we als 'goed' kunnen kwalificeren. We kunnen hiervoor verschillende werkvormen kiezen, of combinaties van elementen uit de socratische methodiek en de morele beraden. In 
de Nederlandse filosofische praktijk zijn vele werkvormen in omloop. Het Vrije ruimte praktijkboek - dat als tweelingdeel is verschenen bij het theoretische boek Vrije Ruimte van Kessels c.s. - bevat vele voorbeelden (Kessels, Mostert \& Boers, 2008). ${ }^{1}$

Een hele bijzondere vorm is het zogeheten kralenspel, ontwikkeld door Jos Kessels, ook wel eidoskoop genoemd, van eidos, idee of vorm, en skoop, ergens naar kijken (Kessels, 2012; www.eidoskoop.nl). Het is de bedoeling het goede idee, in de zin van Plato's filosofie, op het spoor te komen. Volgens Plato bestaan de ideale vormen alleen in de abstracte ideeënwereld. Daar is een cirkel echt rond; in het echte leven is er altijd een minuscule, door materie veroorzaakte afwijking. Ons idee van 'het goede' is perfect, onze praktijken zijn dat nooit. In het kralenspel probeert men bij een vraag of kwestie een goed, perfect idee te vinden dat richting kan geven aan het praktisch handelen. Kessels beschrijft de basisoefening kernachtig als 'het onderzoek van een kwestie aan de hand van de vier oorzaken, de drie centra van motivatie, de twee polen van het denken en het ene centrale Idee' (website eidoskoop). De eerste vier vragen, over de 'oorzaken', beogen de feiten te inventariseren: wat is de situatie (1), wanneer werd het spannend (2), wat gaat er mis als niemand ingrijpt (3), en wat is hierbij de vraag waar het blijkbaar om draait (4)? $\mathrm{Na}$ deze verzameling (of selectie) van relevante feiten volgen drie vragen die de ethiek centraal stellen en onderzoek doen naar de 'drie centra van motivatie'. Buik: welke angst, schroom of onzekerheid speelt hier en moet beheersbaar blijven (5)? Hart: welke moeilijke waarheid moet de persoon of het team (over de opdracht, het probleem, zichzelf) onder ogen zien, wat gaat hem of haar aan het hart (6)? Hoofd: welk ethisch principe of welke hogere waarde is hier in het geding (7)? Als de oorzaken in de vorm van feiten, en de ethische problematiek in de vorm van drie motivaties, zijn uitgetekend, volgt een dialectische verkenning van het speelveld dat zich bevindt tussen 'de twee polen van het denken'. De vraag is hier: binnen welke grenzen is het ethisch verantwoord en mentaal mogelijk om te opereren: doe niet te weinig en maak het niet te klein (8), doe niet te veel en maak het niet te groot (9). Als deze vragen zijn beantwoord is de eindvraag: wat is hierbij het 'goede idee' dat richting kan geven (10)? Kessels schrijft Idee met een hoofdletter, conform de juiste platoonse traditie.

Geoefende 'kralenspelers' kunnen hun spel soms in een uur volbrengen. ${ }^{2}$ Complexe teamvragen kunnen gemakkelijk een dag of meer vergen. Het kralenspel structureert de inhoud van het onderzoek aan de hand van de tien vragen ('kralen'), maar laat de werkvorm vrij. Die kan de uitvoerder zelf kiezen, afhankelijk van de bedoeling van de deelnemers. Deze methodiek kan van dienst zijn in persoonlijke begeleiding of coaching, en ook structuur geven aan zelfonderzoek dat in stilte op eigen kracht wordt ondernomen. Het kralenspel is ook erg geschikt als methode om met teams te werken aan een gezamenlijke visie, een beleidsplan of projectplan. Ook als evaluatiemethodiek is het kralenspel inzetbaar om andere typen verhalen boven water te halen dan in reguliere project- of beleidsevaluaties wordt gedaan. ${ }^{3}$ 


\section{Heldenmoed}

Er is een bijzondere reden om deze kralenspelmethodiek in de context van dit betoog over macht en moed aan de orde te stellen. Deze filosofische onderzoeksmethode helpt namelijk te doorgronden welke machten op iemand inwerken, wat deze persoon zelf zou 'willen' en welke moed dan nodig is om te blijven staan voor deze persoonlijke, ethische wil.

De drie vragen die de ethiek van de persoon of het team in kaart brengen (nummers 5, 6 en 7), verwijzen naar de narratieve structuur die we kennen uit de mythen, de sprookjes, de religieuze verhalen en de grote wereldliteratuur. We volgen in die verhalen een held. Die heeft een taak, een missie, een heilig doel. Maar de held deinst aanvankelijk terug voor de risico's. De held vraagt zich af of hij werkelijk zijn huidige bestaan op het spel moet zetten. Ondanks de vrees voor een slechte afloop ziet de held in dat het heilig moeten hem tot actie noopt. Hij gaat het avontuur aan, niet omdat hij zichzelf wil slachtofferen, maar wel omdat hij bereid is een zwaar offer te brengen in het belang van het hogere doel. Hij offert liever niks, maar als het moet is hij ertoe bereid.

De held ontkomt er niet aan zich deugdzaam te gedragen. Om zijn angsten te bedwingen zal hij temperantia moeten tonen: hij zal zich moet beheersen, hij mag zich niet laten leiden door zijn vrees. Die moet beteugeld worden. Dit is vraag 5 uit het kralenspel, door Kessels betiteld als 'monsters'. Om de goden te dienen zal hij bovendien prudentia moeten betrachten, bezonnenheid moeten tonen. Hij zal het hogere doel, het leidende principe voor ogen moeten houden. Want wie de ethische taak niet respecteert, kan niet goed op reis. Deze vraag 7 uit het kralenspel heeft Kessels 'boodschap van de goden' genoemd. Het komt na vraag 5 en 7 aan op het juiste gedrag van 'de held', de belichaming van vraag 6 . Deze zesde vraag of kraal vormt het centrum van het hele kralenspel. Hier staat de actor centraal, precies zoals Peter Bieri dat bedoelde in zijn standaardwerk over vrijheid en de eigen wilsvorming (Bieri, 2006). De actor is het individu of het team dat zich gesteld ziet voor een taak, een opgave, een vraag, een lastige klus. Deze held kan de eigen angst of de risico's die gloren maar beter niet ontkennen. Dat zou kunnen leiden tot overmoedigheid, hybris. De held van het verhaal mag evenwel ook de andere kant niet vergeten en zich er te gemakkelijk van afmaken. De herinnering aan de boodschap van de goden moet voorkomen dat de held een antiheld wordt en ten prooi valt aan laksheid en lafheid. De persoon of de groep die zichzelf als held in het verhaal plaatst, zal de juiste moed moeten tonen, fortituda. De held zal klaarheid moeten brengen en zich bereid moeten verklaren bepaalde verliezen, offers, acceptabel te vinden. Wie in de strijd niks wil verliezen, blokkeert alles. Die komt niet echt in beweging. De held moet onder ogen zien wat hier op het spel staat en bereid zijn daarvoor een passend offer te brengen.

Dit is een adequate duiding van positie en rol van de tegenspreker. Wie bang is voor de macht zal zwijgen. Wie de moraal daarbij uit het oog verliest, heeft geen recht van spreken. Wie de moed wil opbrengen de macht te weerstaan, zal het risico van een offer moeten aangaan. Tegenspraak is niet voor bange mensen, maar nodig op 
z'n tijd. Dit is de kortste versie van het betoog dat ik in Macht en moed heb opgebouwd. Ambtenaren zouden elkaar moeten helpen om moed te verzamelen die nodig is de macht van bestuurders en politici te weerstaan indien zij niet de rechtsstaat dienen, maar bezig zijn met 'politiek met de kleine p'.

\section{Noten}

1 Naar verwachting komt er in 2022 een nieuw boek met praktisch-filosofische methoden op de markt waarin enkele tientallen praktijkvormen worden beschreven.

2 Dat is overigens niet hetzelfde als 'de kwestie oplossen'. Spelers krijgen inzichten en natuurlijk kunnen die zeer behulpzaam zijn bij het oplossen van problemen.

3 Zie bijvoorbeeld het digitale boek Pijn en pracht, Ruimte voor de rivier van verhalen van Erik Pool en Roelof van de Weg (red.) (2021).

\section{Literatuur}

Arendt, H. (2020). Het leven van de geest. Utrecht: Uitgeverij Ten Have.

Aristoteles (2011). Politica. Groningen: Historische Uitgeverij.

Bekker, R. (2020). Dat had niet zo gemoeten! Fouten en falen van de overheid onder een vergrootglas. Den Haag: Boom bestuurskunde.

Bieri, P. (2006). Handwerk van de vrijheid. Over de ontdekking van de eigen wil. Amsterdam: Wereldbibliotheek.

Brenninkmeijer, A. (2019). Moreel Leiderschap. Amsterdam: Prometheus.

Dohmen, J. (2007). Tegen de onverschilligheid. Pleidooi voor een moderne levenskunst. Amsterdam: Ambo.

Frequin, M. (2021). Reisverslag: uit het land van overheidsleiderschap. Den Haag: Algemene Bestuursdienst.

Hart, P. 't (2014). Ambtelijk vakmanschap 3.0: Zoektocht naar het handwerk van de overheidsmanager. Den Haag: Vereniging voor Overheidsmanagement/Vereniging van Gemeentesecretarissen/Stichting IKPOB.

Kessels, J. (1997). Socrates op de markt. Filosofie in bedrijf. Amsterdam: Boom.

Kessels, J. (2012). Spelen met ideeën. De kunst van het filosofisch gesprek. Amsterdam: Boom.

Kessels, J., Mostert, P., \& Boers, E. (2008). Vrije ruimte praktijkboek, filosoferen in organisaties. Amsterdam: Boom.

Koole, R. (2021). Twee pijlers. Het wankele evenwicht in de democratische rechtsstaat. Amsterdam: Prometheus.

Parlementaire Ondervragingscommissie Kinderopvangtoeslag (2020). Nr. 2 Brief van de parlementaire ondervragingscommissie, 17 december.

Pool, E. (2014). Aanwijzingen voor het goede leven. Over levenskunst en de zoektocht naar zin. Amsterdam: Boom.

Pool, E. (2017). Weerwoord en waarheid. Essay over tegenspraak in de context van het ministerie van Infrastructuur en Milieu. Den Haag: Ministerie van Infrastructuur en Milieu.

Pool, E. (2018). Liefde en leiderschap. Essays over tegenspraak, intimiteit en het goede gesprek. Den Haag: Ministerie van Infrastructuur en Waterstaat.

Pool, E. (2020). De kunst van het leven. Essays over schrijvers, ontwerpers en filosofen. Nootdorp: Werkmetlef.

Pool, E. (2021). Macht en moed. Ambtelijk vakmanschap en de kunst van het tegenspreken. Den Haag: Ministerie van Infrastructuur en Waterstaat. 
Erik Pool

Pool, E., \& Weg, R. van de (2021). Pijn en pracht. Ruimte voor de rivier van verhalen. Den Haag: Ministerie van Infrastructuur en Waterstaat/Kennisknooppunt Participatie.

Roovers, D. (2016). Woord vooraf. In: M.J. Sandel, Politiek en moraal. Filosofie voor het publieke debat. Utrecht: Ten Have.

Sluiter, I. (2014). Socrates (Elementaire deeltjes 3). Amsterdam: Athenaeum.

Taylor, C. (1989). Bronnen van het zelf. Rotterdam: Lemniscaat.

Tjeenk Willink, H. (2021). Kan de overheid crises aan? Waarom het belangrijk is om groter te denken en kleiner te doen. Amsterdam: Prometeus.

Verbrugge, A (2004). Tijd van onbehagen. Filosofische essays over een cultuur op drift. Amsterdam: Boom.

www.eidoskoop.nl, geraadpleegd 6 oktober 2021.

www.isvw.nl/activiteit/moreelberaad-2022/, geraadpleegd 6 oktober 2021.

www.kennisknooppuntparticipatie.nl/actueel/nieuws/1961658.aspx, geraadpleegd 21 oktober 2021. 